\title{
Design and Implementation of an Intelligent Classroom Teaching System for Music Class Based on Internet of Things
}

\author{
https://doi.org/10.3991/ijet.v16i18.25665 \\ Dong Lyu ${ }^{(\varpi)}$, Zhiying Wang \\ Hebei Institute of Communications, Shijiazhuang, China \\ winter886666@163.com
}

\begin{abstract}
The intelligent classroom teaching system can analyze the student features and teaching content, and then push the suitable content to students. With the aid of such a system, teachers can develop more flexible teaching strategies, and evaluate the student performance more accurately. Drawing on the theories of the Internet of things (IoT), this paper designed an intelligent classroom teaching system for music teachers, and applied the system to actual teaching practice. The results showed that the proposed system provided music teachers with an ideal tool of teaching design; the network structure of the system consists of collaborative, master, camera monitoring, and standby servers; the proposed system was found to satisfy all requirements through repeated tests. The research results provided a good theoretical support to the application of IoT in teaching design.
\end{abstract}

Keywords-intelligent classroom teaching, teaching content, teaching strategies, Internet of things (IoT), network structure

\section{Introduction}

The intelligent features of an intelligent teaching system are mainly reflected in aspects of student personality, discipline features, and situational influence, etc. [1]. The decision-making and reasoning mechanism plays a critical role in the intelligence performance and effectiveness of an intelligent teaching system [2, 3]. An intelligent teaching system generally contains modules such as teacher module, student module, and course module, and it should have a complete database system which is operated, managed, and maintained by the database server [4]. Student-centered is the most prominent feature of such intelligent teaching system, and it can fully reflect the teaching strategies, control strategies, and reasoning rules, etc. [5].

Theoretically, an intelligent classroom teaching system integrated the basic theories of pedagogy, applied the technical features of IoT, and intelligently realized the development of education based on IoT technologies [6, 7]. To establish an intelligent classroom teaching system, works should start from knowledge expression, reasoning function, student module, course module, and teacher module [8,9]. 
Through the interactive dialogue between students and computers, the simulated teaching process instructs students to perform lesson learning, homework exercising, and test and exam information processing, etc. [10]. The intelligent classroom teaching system is an intelligent and heuristic programming system that can use expert knowledge and experience to reason [11,12].

Based on the complex, uncertain, and fuzzy features of the intelligent teaching system, the design of classroom teaching should take students as the core [13]. The key to teaching design is the design of teaching content, methods, and resources; when developing online courses, the teaching design needs to combine with the characteristics of each course from different perspectives, and research the necessity of following certain teaching design theories when developing the online courses [14]. The intelligent classroom teaching system includes two processes: knowledge representation, and decision reasoning. Wherein knowledge representation contains: representation ability, usability, organizability, maintainability, realizability, naturalness and understandability $[15,16]$. The application of IoT technology in the classroom teaching system can realize intelligent perception of the behaviors of teachers and students, the status of the equipment, and the safety status of laboratories, and it can automatically calculate the utilization rate of multimedia equipment and laboratory equipment [17]. Based on IoT technology, this paper explores its application in the design of a classroom teaching system for music class, in the hopes of providing a support for the research on the application of IoT technology in teaching design.

\section{Design of the IoT-based teaching information mining system}

Most colleges and universities in China have built basic digital campus platforms, and these teaching information management systems based on campus IoT have integrated teacher information, class hour information, and class information, etc. [18, 19]. The use of IoT enables the faculty and students to query information, work online, pay bills on campus, receive and send emails, and deal with various transactional affairs [20, 21]. Now some schools have applied IoT and big data technologies to their teaching information management systems, the schools can quickly obtain students' class attendance status via the Internet, and students can get the information of courses and homework via personal terminals [22]. The traditional classroom teaching systems generally consist of browser ends and a server database system. Figure 1 shows the architecture of the IoT-based classroom teaching information system. Compared with traditional classroom teaching systems, this new system added an information acquisition module, it can automatically collect information of the teaching status in classrooms. The automatic information acquisition module uses intelligent cameras, card readers, and infrared sensors, and all collected information can be transmitted to the gateway system through the bus [23, 24].

IoT mainly contains three parts: the sensor network, the Internet-end applications, and the connection link between the two [25]. When the data collected by the 
acquisition module of IoT is being transmitted to the server through the network layer, a gateway is needed to convert the communication protocol in the middle [26, 27]. The gateway module is the root node of the acquisition sub-system network, it manages every acquisition sub-module under the communication network [28]. The mining of teaching information needs to borrow the help of the reasoning system [29, 30]. The reasoning decision in classroom teaching design means that teachers who are responsible for the courses formulate their teaching methods according to their own teaching strategies based on various information collected by the system, including the student information, teaching information, and system information, etc. [31]. Figure 2 shows the workflow of information mining and reasoning. The classroom teaching information system forms the activity flow of system decision reasoning through information collection, information analysis, application strategy, student selection, and reasoning control. The application strategy module is a function of the reasoning control module, it is a process of reasoning control, which can generate relevant classroom teaching design methods for students to choose [32, 33].

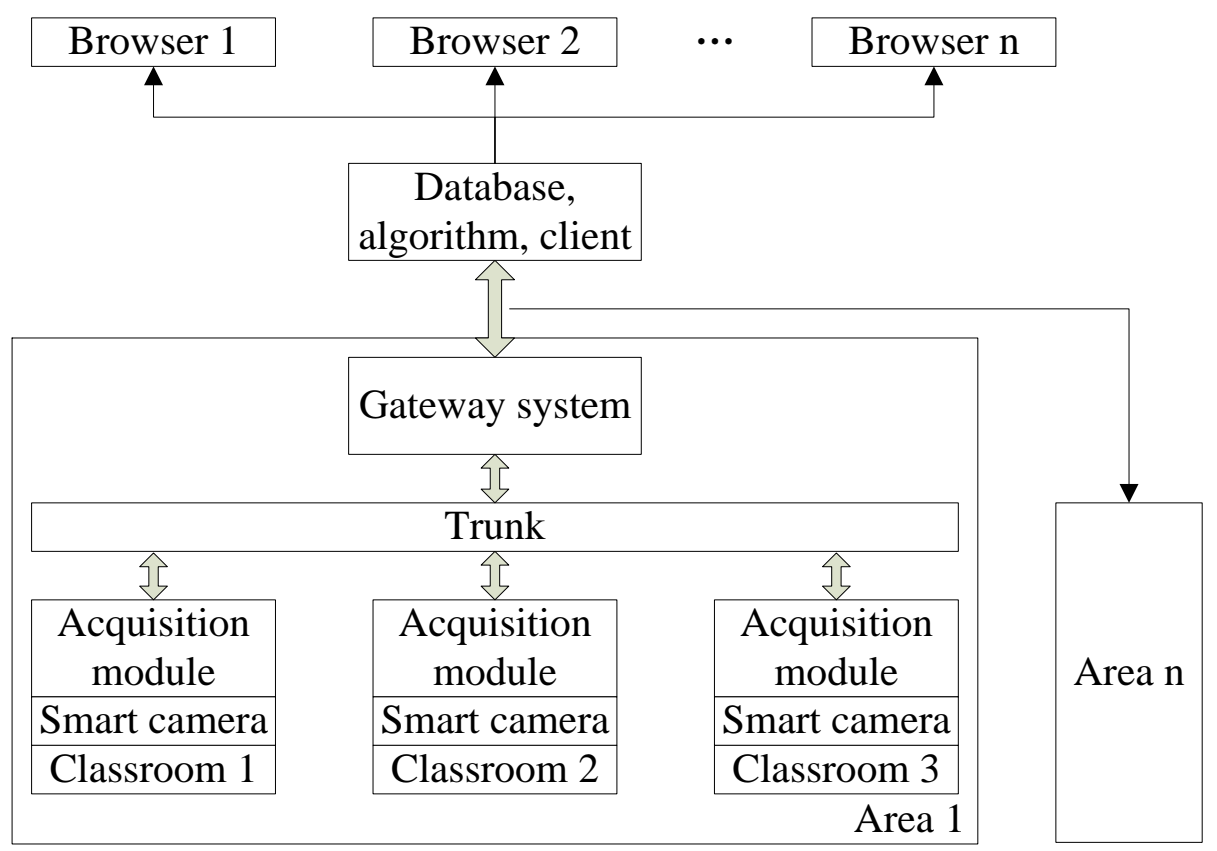

Fig. 1. Architecture of the IoT-based classroom teaching information system 


\begin{tabular}{|c|}
\hline $\begin{array}{c}\text { Classroom teaching information } \\
\text { system }\end{array}$ \\
\hline Classroom information collection \\
\hline Classroom information analysis \\
\hline Application strategy \\
\hline 5 \\
\hline Student choice \\
\hline 5 \\
\hline Inferential control \\
\hline Activity flow \\
\hline
\end{tabular}

Fig. 2. Workflow of information mining and reasoning

\section{Modeling of the intelligent classroom teaching system for music class}

\subsection{Overall design of the intelligent classroom teaching system}

The intelligent classroom teaching system is a special application field, by analyzing the intelligent teaching information system, a reasonable structural model could be established, and the functions of the intelligent classroom teaching system could be realized via the reasoning mechanism [34]. The intelligent classroom teaching system can assist and deepen the teaching behaviors, besides performing quantitative reasoning based on quantitative models or prediction models, it also needs to perform qualitative reasoning on a large amount of uncertain knowledge based on teachers' experience and knowledge. Figure 3 shows the architecture of the intelligent teaching system. The system contains three parts: student model, teaching model, and domain model; wherein, the domain model contains the resource model and the control model; and the teaching model is a stable structural form of the teaching activity progress developed in a certain environment under the guidance of educational thoughts, educational theories and learning theories.

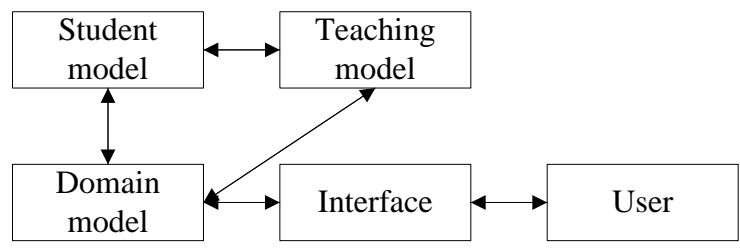

Fig. 3. The architecture of intelligent teaching system 
Figure 4 shows the relationships among the modules of the teaching system. With the help of the IoT-based teaching system, this study selected the attendance module for analysis, the attendance information of teachers and students could be recorded by the routers, we used cameras to shoot the required router images, and the server was used to score, cut, query, or display the attendance information. Figure 5 shows the classification of intelligent teaching modes. Generally, the intelligent teaching modes are divided into four categories: the mode dominated by collective learning, the mode dominated by individual learning, and discussion learning mode dominated by group learning, and the collaborative learning mode. Teaching modes are realized through the implementation of teaching process, and the entire teaching process adopts different teaching design methods according to the different teaching modes. The entire teaching activities can be decomposed into several independent and interconnected links and stages, and each teaching link or stage can also be decomposed into independent and interconnected sub-links

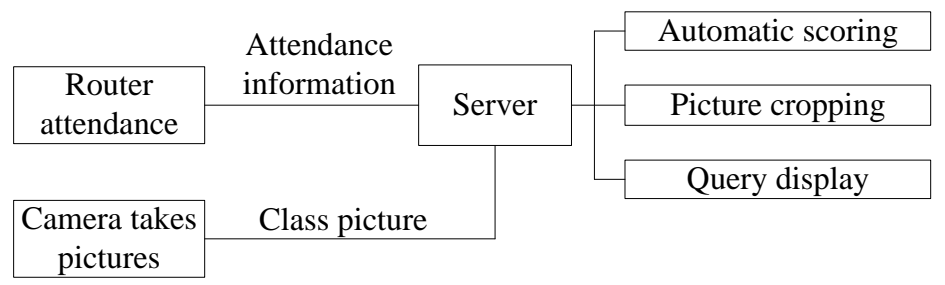

Fig. 4. Relationship between modules of the teaching system

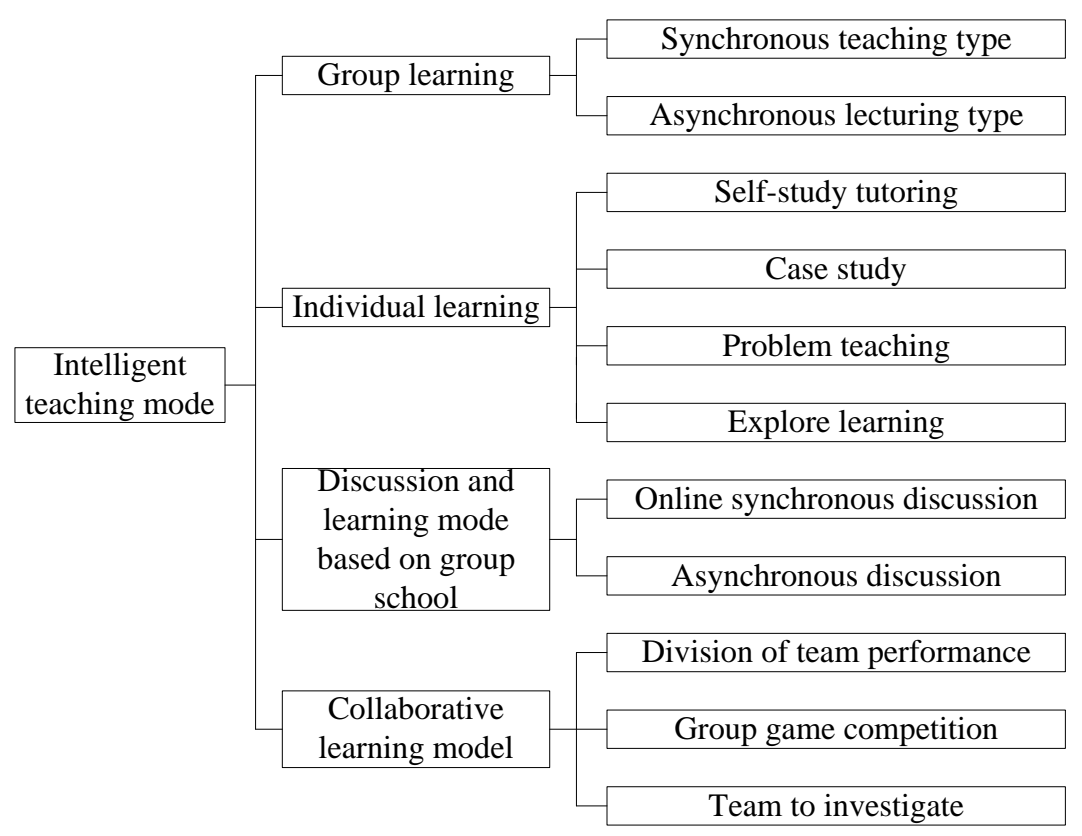

Fig. 5. Classification of intelligent teaching modes 
Figure 6 shows the overall architecture of the intelligent classroom teaching system. The entire system is divided into four layers: access layer, application layer, service layer, and resource layer. The application layer has four parts: schedule management, course management, exam management, and teaching evaluation; the service layer includes: data exchange, security certification, user management, interface management, configuration management, monitoring management, behavior log, and access control. Each system layer realizes data exchange and management of the teaching system based on system security and monitoring principles.

Figure 7 is the architecture of the software system of the intelligent classroom teaching system. The figure intuitively gives the interactive relationships among different layers. The front-end operation interface is responsible for receiving operation requirements of the users; after such operation requirements are received, the corresponding communication interface would perform file configuration

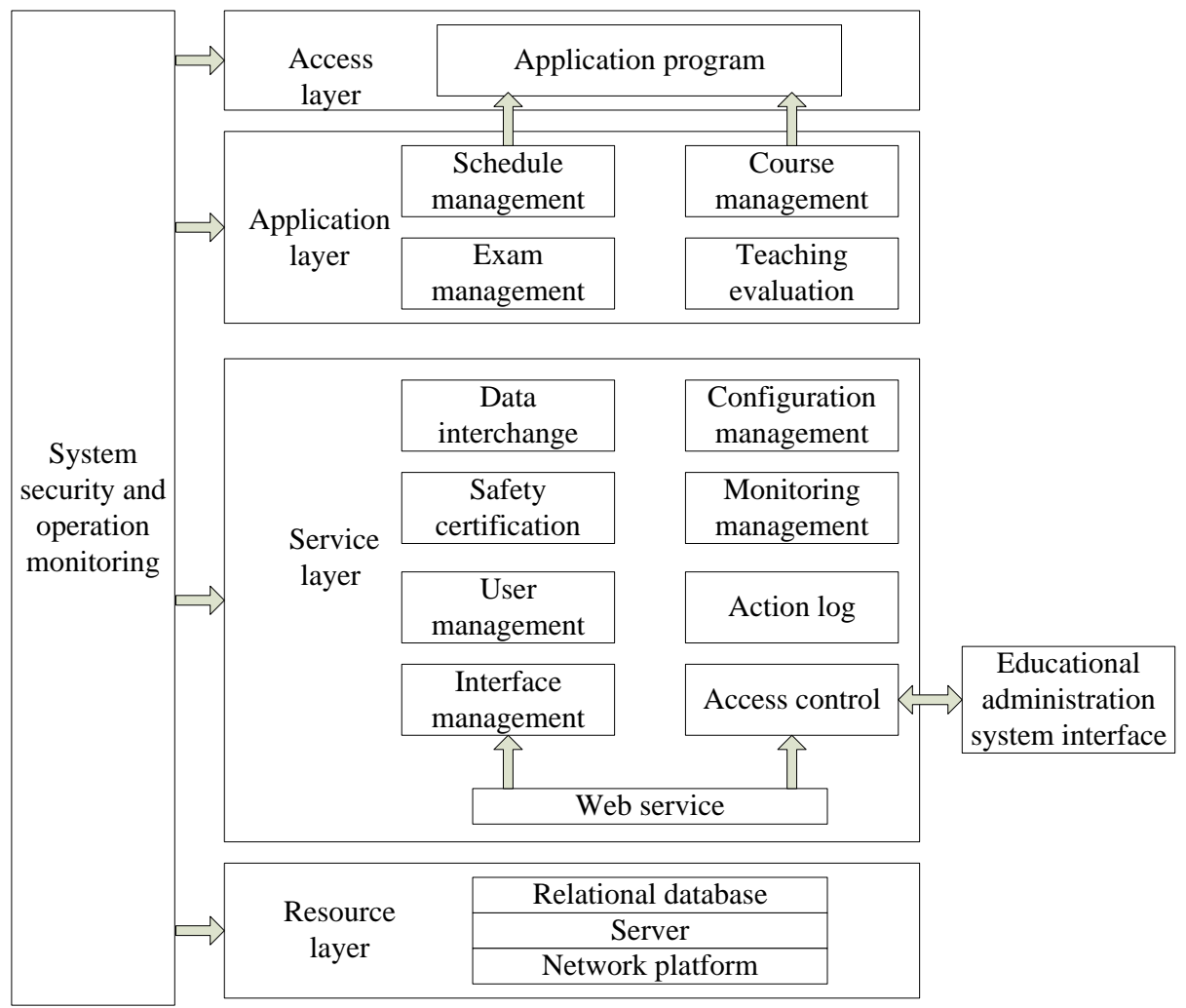

Fig. 6. Overall architecture of intelligent classroom teaching system 


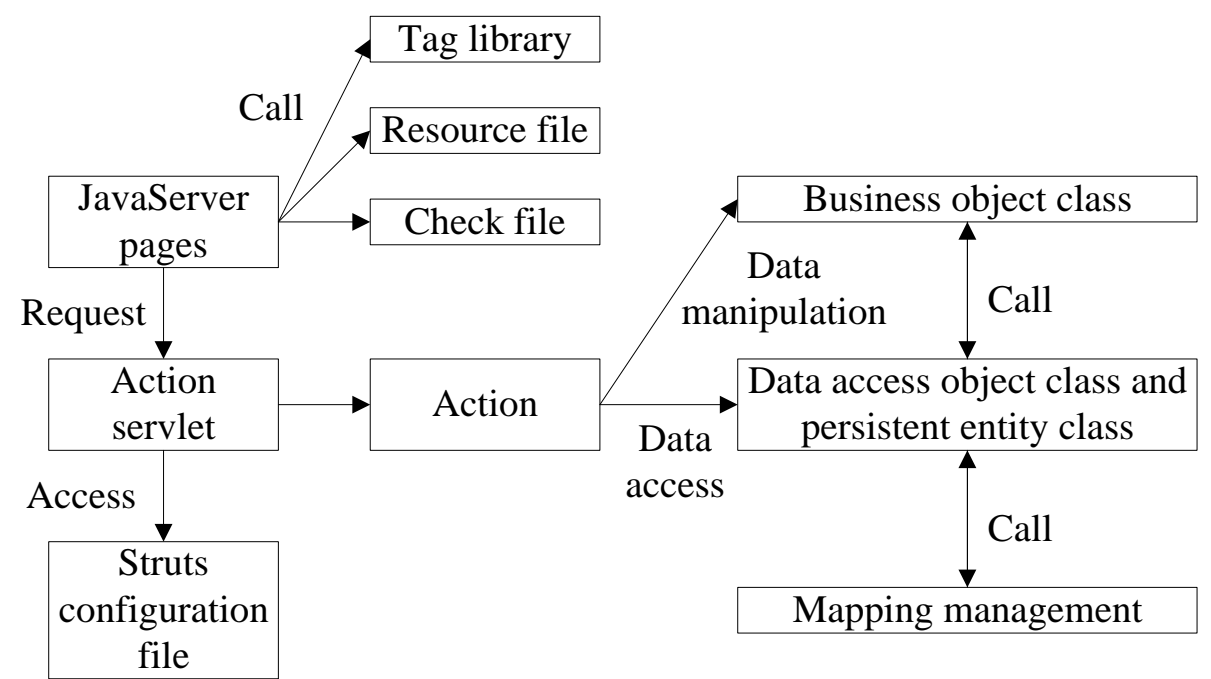

Fig. 7. Architecture of the software system of the intelligent classroom teaching system

\subsection{Implementation plan of the intelligent classroom teaching system for music class}

The intelligent classroom teaching system for music class is a teaching design tool for music teachers. Figure 8 is a diagram of the basic information management function. It includes five parts: student information management, teacher information management, classroom information management, course information management, and class information management. The intelligent classroom teaching system controls each classroom through a central control system, and the central control systems of each classroom are connected via the campus network, Figure 9 shows the network structure of the intelligent classroom teaching system. The collaborative server, master control server, camera monitoring server and standby server are set on the cloud side; the master server is responsible for teaching management, it collects the big data of the behaviors of teachers and students. The camera monitoring server is mainly used to manage the closed-circuit surveillance cameras installed in each classroom. The collected data can be taken as teaching materials to assist the teaching design. Figure 10 shows an intelligent classroom system. The intelligent classroom system includes multimedia teaching, educational administration management, attendance management, and classroom video surveillance. When the central control system in the classroom receives the command to turn on the teaching equipment, it will turn on the client-end of the multimedia teaching management system in the classroom, and automatically start all teaching-related devices. 


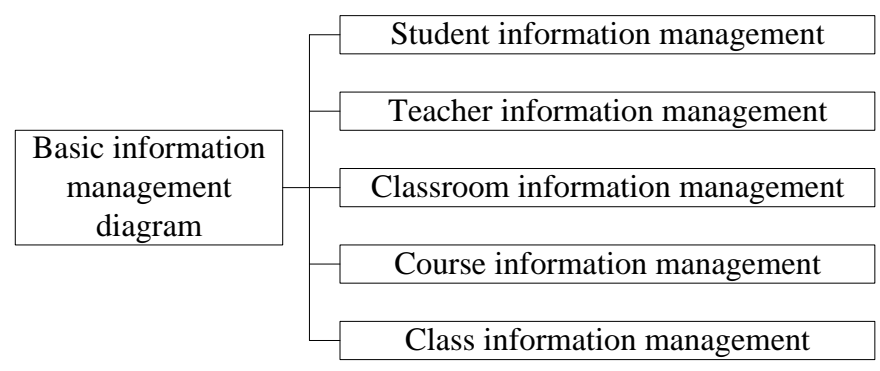

Fig. 8. A diagram of the basic information management function

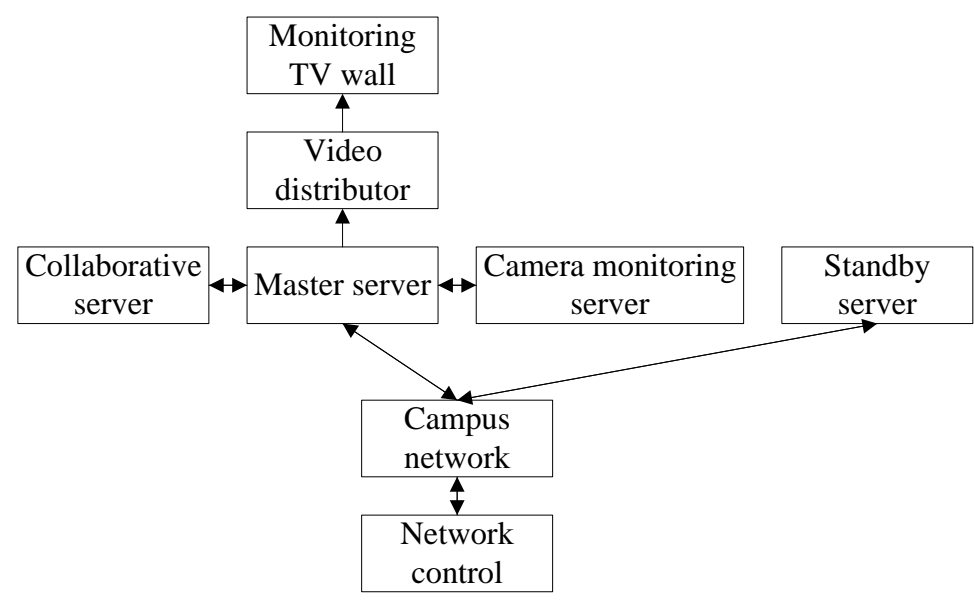

Fig. 9. Network structure of intelligent classroom teaching control system

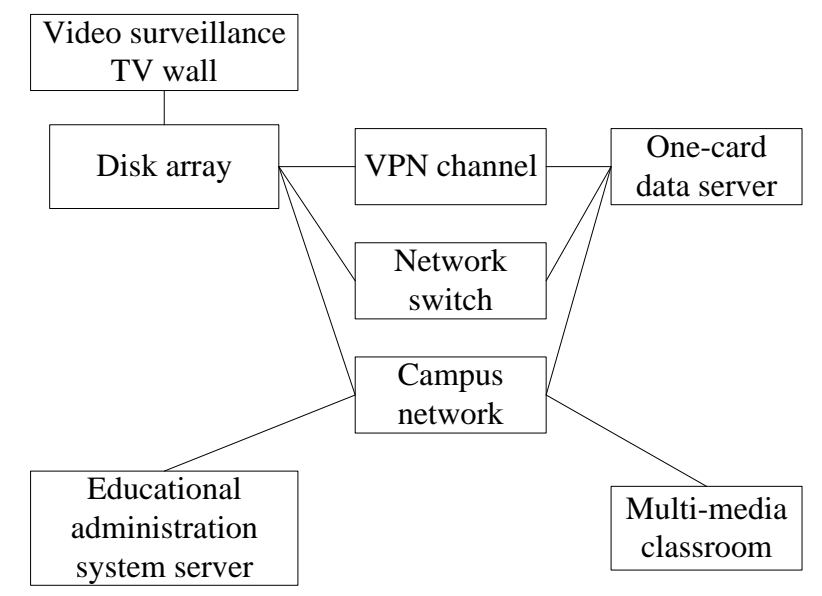

Fig. 10. Intelligent classroom system 


\section{Design and implementation of the intelligent classroom teaching system for music class}

\subsection{Design of the intelligent classroom teaching system for music class}

Teachers are the designers of intelligent classroom teaching, and the selection of teaching mode and the organization and arrangement of teaching design process are the manifestations of the teachers' implicit teaching knowledge. Table 1 shows the specific manifestation forms of the behaviors of teachers and students. A teacher's behaviors generally include explain, demonstrate, blackboard-writing, and use various media forms to give prompts, raise questions, call the roll, evaluate, and give feedback, etc. A student's behaviors generally include speak, think, calculate, take notes, and do homework, etc. Taking the open class "Music Appreciation" of Zhejiang University as an example, the teaching videos of the course were subject to teaching analysis, and the results showed that, a few minutes before the teaching, students' behaviors showed a large growth, while the teacher's behaviors didn't show significant changes; in the middle of the class, both the behaviors of students and the teacher showed a gradual and smooth growth, indicating that students and the teacher had formed a good interaction; by the end of the class, students' behaviors showed another growth for a relatively long period of time.

Table 1. Specific manifestation forms of the behaviors of teachers and students

\begin{tabular}{|c|c|c|c|}
\hline Category & Manifestations & Category & Manifestations \\
\hline \multirow{6}{*}{ Teacher behavior } & Commentary & \multirow{6}{*}{ Student behavior } & Student speeches \\
\hline & Demonstration & & Students' thinking and calculation \\
\hline & Blackboard writing & & Students take notes \\
\hline & Display in various media & & $\begin{array}{l}\text { Students do experiments or finish } \\
\text { their homework }\end{array}$ \\
\hline & Questions and roll call & & Silence \\
\hline & Evaluation and feedback & & Other \\
\hline
\end{tabular}

A greater occupancy rate of teacher behavior indicates the teacher's behaviors are more prominent. The behavior conversion rate describes the interaction between teacher and student during teaching, the greater the behavior conversion rate, the higher the frequency of the shifting between the behaviors of the teacher and the behaviors of students. Figure 11 gives the relationship between the occupancy rate of teacher behavior and the behavior conversion rate, when both the two rates are not high, the class behaviors are called the practice-type behaviors; with the increase of the occupancy rate of teacher behavior, the class behaviors gradually change to the lecture-type and conversational-type behaviors; when the occupancy rate of teacher behavior is in a middle position and the behavior conversion rate is relatively high, the class behaviors are called the hybrid-type behaviors. Figure 12 shows the interaction hierarchies of classroom teaching in the music class. The interactive hierarchical model divides the learning process into three hierarchies, namely the 
operation interaction, the information interaction, and the concept interaction. Wherein, the operation interaction is the interaction between students and the media interface; information interaction includes teacher-student interaction, student-student interaction, and the interaction between students and learning resources. The whole process transforms from specific to abstract, and from low-level to high-level.

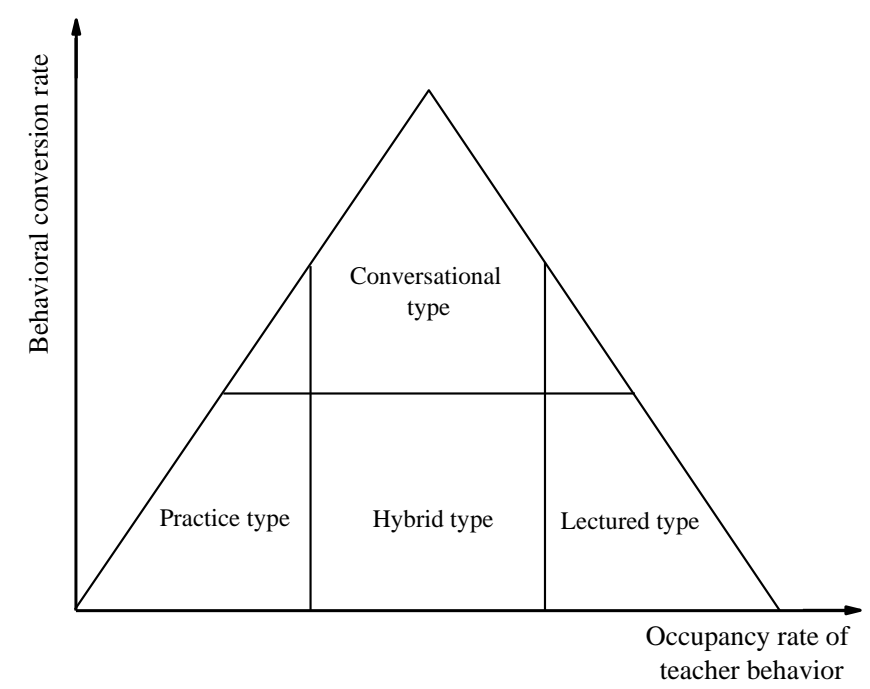

Fig. 11. Relationship between the occupancy rate of teacher behavior and the behavior conversion rate

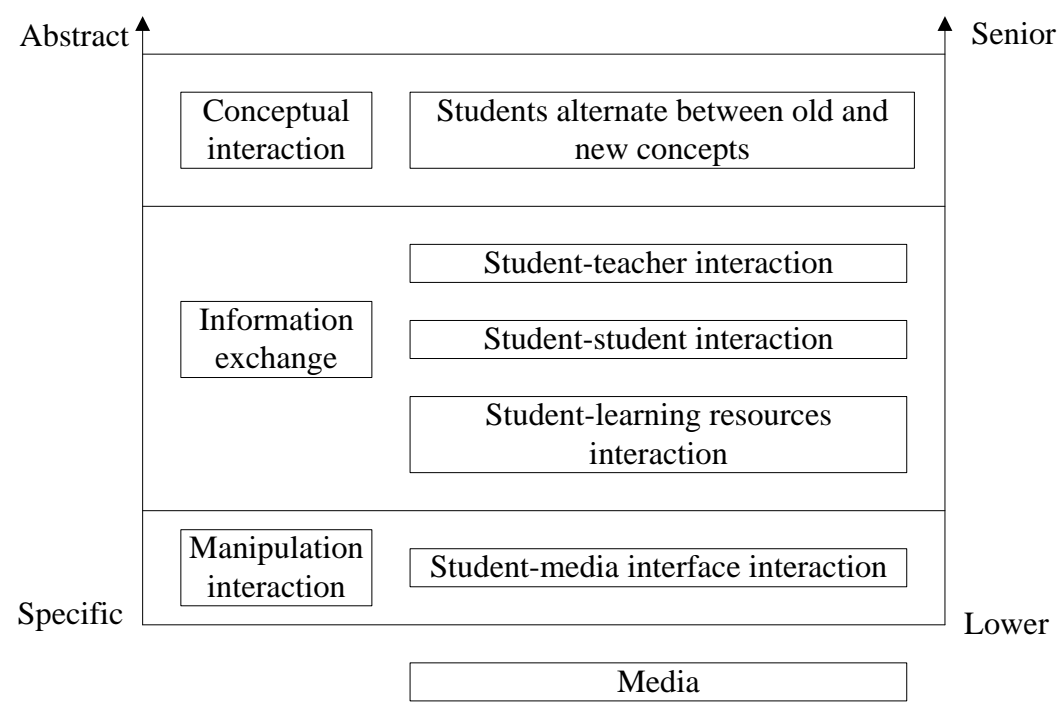

Fig. 12. Interaction hierarchies of classroom teaching in the music class 


\subsection{Testing of the intelligent classroom teaching system for music class}

The main function of the IoT-based server is to update course information, give and display scores automatically, and classroom teaching analysis, etc. Figure 13 shows the teaching principles of the intelligent classroom teaching for music class, it mainly includes the principles of subjectivity, difference, harmony, and selectivity. Teachers need to make the music teaching more harmonious, pay attention to the advantages of every student, and create a diversified learning environment for students. When doing the teaching design, teachers shouldn't copy the existing teaching designs mechanically, the teaching design should take teaching content as the core, and make use of the intelligent classroom teaching system selectively. The development process of the intelligent classroom teaching system for music class realized the module functions according to the design requirements, and the functions include the router attendance record function; camera shooting, recording, and saving function; and comprehensive evaluation function, etc. After debugging, the proposed intelligent classroom teaching system for music class was found to be able to meet the relevant requirements.

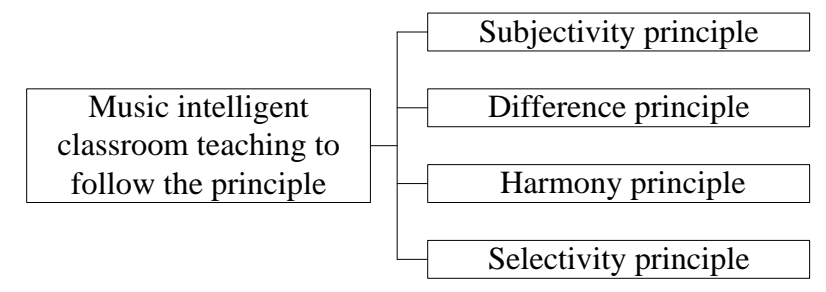

Fig. 13. Teaching principles of the intelligent classroom teaching for music class

\section{Conclusion}

Based on the theory of IoT, this paper explored its application in the design of an intelligent classroom teaching system for music class, and the obtained conclusions are:

1. The intelligent classroom teaching system can assist and deepen the teaching behavior, besides performing quantitative reasoning based on quantitative models or prediction models, it also needs to perform qualitative reasoning on a large amount of uncertain knowledge based on teachers' experience and knowledge.

2. The network structure of the intelligent classroom teaching system consists of the collaborative server, master control server, camera monitoring server and standby server set on the cloud side; the master server is responsible for teaching management, it collects the big data of the behaviors of teachers and students.

3. The interaction hierarchies of classroom teaching in the music class have three hierarchies of operation interaction, information interaction, and concept interaction. After debugging, the proposed intelligent classroom teaching system for music class was found to be able to meet the relevant requirement. 


\section{References}

[1] Wu, L., Mcmahon, M. (2014). Adopting a musical intelligence and e-learning approach to improve the English language pronunciation of Chinese students. AI \& society, 29(2): 231-240. https://doi.org/10.1007/s00146-013-0479-6

[2] Zheng, X., Neil, Y. (2019). Special issue on emergence in human-like intelligence toward cyber-physical systems. Neural Computing and Applications, 31(9): 4451-4453. https://doi.org/10.1007/s00521-019-04033-y

[3] Tutwiler, S., Lin, M.C., Chang, C.Y. (2013). The use of a gesture-based system for teaching multiple intelligences: A pilot study. British Journal of Educational Technology, 44(5): E133-E138. https://doi.org/10.1111/j.1467-8535.2012.01368.x

[4] Zhou, D., Liu, L., Tang, T., Huang, Y, Hong, J. (2020). Design on intelligence music system in the cultural center based on iot. Personal and Ubiquitous Computing, 24(3): 319332. https://doi.org/10.1007/s00779-019-01245-w

[5] Wen, X. (2020). Using deep learning approach and iot architecture to build the intelligent music recommendation system. Soft Computing, 25(4): 3087-3096. https://doi.org/10. 1007/s00500-020-05364-y

[6] López-Ortega, O., Castro-Espinoza, F., Pérez-Cortés, O. (2018). An intelligent multi-agent system to create and classify fractal music. Computing: Archives for informatics and numerical computation, 100(7): 671-688. https://doi.org/10.1007/s00607-017-0584-3

[7] Chiu, M.C., Ko, L.W. (2017). Develop a personalized intelligent music selection system based on heart rate variability and machine learning. Multimedia Tools \& Applications, 76(14): 15607-15639. https://doi.org/10.1007/s11042-016-3860-x

[8] Magnusson, L. (2011). Comparison of the fine structure processing (fsp) strategy and the cis strategy used in the med-el cochlear implant system: speech intelligibility and music sound quality. International Audiology, 50(4): 279-287. https://doi.org/10.3109/14992027 $\underline{.2010 .537378}$

[9] Prisco, R.D., Guarino, A., Lettieri, N., Malandrino, D., Zaccagnino, R. (2021). Providing music service in ambient intelligence: experiments with gym users. Expert Systems with Applications, 177: 114951. https://doi.org/10.1016/j.eswa.2021.114951

[10] Rodgers, W., Yeung, F., Odindo, C., Degbey, W.Y. (2021). Artificial intelligence-driven music biometrics influencing customers' retail buying behavior. Journal of Business Research, 126: 401-414. https://doi.org/10.1016/j.jbusres.2020.12.039

[11] Kim, S.T., Oh, J.H. (2021). Music intelligence: granular data and prediction of top ten hit songs. Decision Support Systems, 145(2): 113535. https://doi.org/10.1016/j.dss.2021. $\underline{113535}$

[12] Kalaganis, F.P., Adamos, D.A., Laskaris, N.A. (2018). Musical neuropicks: a consumergrade bci for on-demand music streaming services. Neurocomputing, 280(S1): 65-75. https://doi.org/10.1016/j.neucom.2017.08.073

[13] Zhou, Y., Ouyang, M., Shu, S. (2021). Artificial intelligence student management based on embedded system. Microprocessors and Microsystems, 83: 103976. https://doi.org/10. 1016/j.micpro.2021.103976

[14] Elbir, A., Aydin, N. (2020). Music genre classification and music recommendation by using deep learning. Electronics Letters, 56(12): 627-629. https://doi.org/10.1049/el. $\underline{2019.4202}$

[15] Turchet, L., West, T, Wanderley, M.M. (2020). Touching the audience: musical haptic wearables for augmented and participatory live music performances. Personal and Ubiquitous Computing, 0(0): 1-21. https://doi.org/10.1007/s00779-020-01395-2 
Paper-Design and Implementation of an Intelligent Classroom Teaching System for Music Class Based...

[16] Gioti, A.M. (2020). From artificial to extended intelligence in music composition. Organised Sound, 25(1): 25-32. https://doi.org/10.1017/S1355771819000438

[17] Lvarez, P., Zarazaga-Soria, F.J. Baldassarri, S. (2020). Mobile music recommendations for runners based on location and emotions: the dj-running system. Pervasive and Mobile Computing, 67: 101242. https://doi.org/10.1016/j.pmcj.2020.101242

[18] Hadimlioglu, I.A., King, S.A. (2018). Automated musical transitions through rule-based synthesis using musical properties. Entertainment Computing, 28: 59-67. https://doi. org/10.1016/i.entcom.2018.10.004

[19] Turchet, L., Antoniazzi, F., Viola, F., Giunchiglia, F, Fazekas, G. (2020). The internet of musical things ontology. Journal of Web Semantics, 60: 100548. https://doi.org/10.1016 lj.websem.2020.100548

[20] Zhang, R. (2019). The application of fog computing and internet of things technology in music resource management model. IEEE Access, 8: 11840-11847. https://doi.org/10.1109 IACCESS.2019.2963199

[21] Li, W. (2019). Design and implementation of music teaching assistant platform based on internet of things. Transactions on Emerging Telecommunications Technologies, 30(9): e3606. https://doi.org/10.1002/ett.3606

[22] Samarjit, R., Dhiman, S., Sourav, H., Debashis, D. (2018). Internet of music things: an edge computing paradigm for opportunistic crowdsensing. The Journal of Supercomputing , 74(11): 6069-6101. https://doi.org/10.1007/s11227-018-2511-6

[23] Yang, Q. (2021). Cloud music teaching database based on opencl design and neural network - sciencedirect. Microprocessors and Microsystems, 82: 103897. https://doi.org/ 10.1016/j.micpro.2021.103897

[24] Liu X., Yang, C.Y. (2021). Remote music teaching classroom based on embedded system and cloud platform. Microprocessors and Microsystems, 103844. https://doi.org/10.1016/ j.micpro.2021.103844

[25] Mellizo, J. (2020). Music education, curriculum design, and assessment: imagining a more equitable approach. Music Educators Journal, 106(4): 57-65. https://doi.org/10.1177/00 $\underline{27432120917188}$

[26] Wu, H. (2021). Design of embedded dance teaching control system based on fpga and motion recognition processing. Microprocessors and Microsystems, 83(3): 103990. https://doi.org/10.1016/j.micpro.2021.103990

[27] Paney, A.S., Buonviri, N. O. (2014). Teaching melodic dictation in advanced placement music theory. Journal of Research in Music Education, 61(4): 396-414. https://doi.org /10.1177/0022429413508411

[28] Mcferran, K.S., Rickson, D. (2014). Community music therapy in schools: realigning with the needs of contemporary students, staff and systems. International Journal of Community Music, 7(1): 75-92. https://doi.org/10.1386/ijcm.7.1.75_1

[29] Sylleros, A., Patricio, D., R Cádiz. (2014). Designing a musical instrument: enlivening theory through practice-based research. Design Issues, 30(2): 83-96. https://doi.org/10. 1162/DESI_a_00264

[30] Mateos-Moreno, D., Alcaraz-Iborra, M. (2013). Grounded theory as a methodology to design teaching strategies for historically informed musical performance. Music Education Research, 15(2): 231-248. https://doi.org/10.1080/14613808.2013.788139

[31] Oliveira, L.B., Paulino, N., Oliveira, J. (2017). Undergraduate electronics projects based on the design of an optical wireless audio transmission system. IEEE Transactions on Education, 60(2): 105-111. https://doi.org/10.1109/TE.2016.2590999 
Paper-Design and Implementation of an Intelligent Classroom Teaching System for Music Class Based...

[32] Streeter, E., Davies, M., Reiss, J.D., Hunt, A., Roberts, C. (2012). Computer aided music therapy evaluation: testing the music therapy logbook prototype 1 system. Arts in Psychotherapy, 39(1): 1-10. https://doi.org/10.1016/j.aip.2011.11.004

[33] Truman, P.J. (2010). An investigation of the situated learnability effects of single- and dual-modal systems in education: a report of music-oriented learning environment and science computer-assisted teaching studies. British Journal of Educational Technology, 37(1): 131-142. https://doi.org/10.1111/j.1467-8535.2005.00533.x

[34] Jylha, A., Ekman, I., Erkut, C., Tahiroglu, K. (2011). Design and evaluation of humancomputer rhythmic interaction in a tutoring system. Computer Music Journal, 35(2): 3648. https://doi.org/10.1162/COMJ_a_00055

\section{$7 \quad$ Authors}

Dong Lyu, Lecturer, Master of Arts, graduated from Yunnan Art University in 2010 and currently works at Hebei Institute of Communications. The main research areas are music production and recording, and musical education.

Zhiying Wang, Lecturer, Master of Fine Arts, graduated from Hebei Normal University in 2012 and currently works at Hebei Institute of Communications. The main research areas are vocal singing and teaching, and musical education. (email: ying981677@163.com).

Article submitted 2021-07-19. Resubmitted 2021-08-24. Final acceptance 2021-08-29. Final version published as submitted by the authors. 